\title{
TU/e emonownen

\section{Feasibility study of multi-phase machine winding reconfiguration for fully electric vehicles}

\section{Citation for published version (APA):}

Daniels, B., Gurung, J., Huisman, H., \& Lomonova, E. (2019). Feasibility study of multi-phase machine winding reconfiguration for fully electric vehicles. In 2019 14th International Conference on Ecological Vehicles and Renewable Energies, EVER 2019 [8813594] Institute of Electrical and Electronics Engineers.

https://doi.org/10.1109/EVER.2019.8813594

DOI:

10.1109/EVER.2019.8813594

Document status and date:

Published: 01/09/2019

\section{Document Version:}

Accepted manuscript including changes made at the peer-review stage

\section{Please check the document version of this publication:}

- A submitted manuscript is the version of the article upon submission and before peer-review. There can be important differences between the submitted version and the official published version of record. People interested in the research are advised to contact the author for the final version of the publication, or visit the $\mathrm{DOI}$ to the publisher's website.

- The final author version and the galley proof are versions of the publication after peer review.

- The final published version features the final layout of the paper including the volume, issue and page numbers.

Link to publication

\section{General rights}

Copyright and moral rights for the publications made accessible in the public portal are retained by the authors and/or other copyright owners and it is a condition of accessing publications that users recognise and abide by the legal requirements associated with these rights.

- Users may download and print one copy of any publication from the public portal for the purpose of private study or research.

- You may not further distribute the material or use it for any profit-making activity or commercial gain

- You may freely distribute the URL identifying the publication in the public portal.

If the publication is distributed under the terms of Article 25fa of the Dutch Copyright Act, indicated by the "Taverne" license above, please follow below link for the End User Agreement:

www.tue.nl/taverne

Take down policy

If you believe that this document breaches copyright please contact us at:

openaccess@tue.nl

providing details and we will investigate your claim. 


\title{
Feasibility Study of Multi-Phase Machine Winding Reconfiguration for Fully Electric Vehicles
}

\author{
B. Daniels, J. Gurung, H. Huisman and E.A. Lomonova \\ Department of Electrical Engineering, Electromechanics and Power Electronics \\ Eindhoven University of Technology \\ Eindhoven 5612 AZ, The Netherlands \\ B.Daniels@tue.nl
}

\begin{abstract}
This paper presents a feasibility study towards a control technique for a multi-phase machine with independent windings, so-called winding reconfiguration, for application in fully electric vehicles. The goal is to shift the point where field weakening is necessary and avert its dangers, extend the constanttorque region of the machine, and eliminate the torque-pulsations associated with gear shifts. The winding reconfiguration technique is modeled, and compared with measurement data obtained on a test setup featuring a six-phase machine.

Index Terms-Electric vehicles, multi-phase machine, winding reconfiguration, machine control.
\end{abstract}

\section{INTRODUCTION}

The detrimental effect that greenhouse gases have on the delicate balance maintained on earth is well-known. Transportation is responsible for approximately a quarter of the total emitted amount of harmful gases, and the strive to meet emission standards leaves it in need of a major overhaul. The electrification of consumer cars, by the adoption of partial or fully electric vehicles, is a big leap towards this goal [1].

The powertrain of a fully electric vehicle consists of the following main components: the electric machine (EM) that generates the power to drive the vehicle; the power converter that commutates the EM to achieve the desired operation; the gearbox which serves as the mechanical coupling to transfer the generated energy between the EM and the wheels, and allows for extension of the torque-speed range; and the battery where the power is drawn from or stored in. For the EM often a permanent magnet motor is used, due to its high power density, torque generation capability, and high power factor [2]. The power converter consists of MOSFET or IGBT semiconductor switches, to create the currents that drive the EM. The gearbox often consists of a single fixed gear ratio, or two fixed gear ratios combined, i.e. twin speed or dual-clutch. The drivetrain, i.e. gearbox, axles, and differentials, must be kept down in inertia to achieve a fast dynamic response [3]. In vehicles with an internal combustion engine (ICE) the gearbox contains more gear steps, often $5-8$ stages of reduction gears are used.

The goal of the gearbox is to operate the driving machine in the most optimal region at all times, such that power is transferred most efficiently. For EMs the full torque is available from standstill, compared to the ICE, which has to run at all times. Therefore, fewer gear ratios are required to obtain a desirable torque production over a wide speed

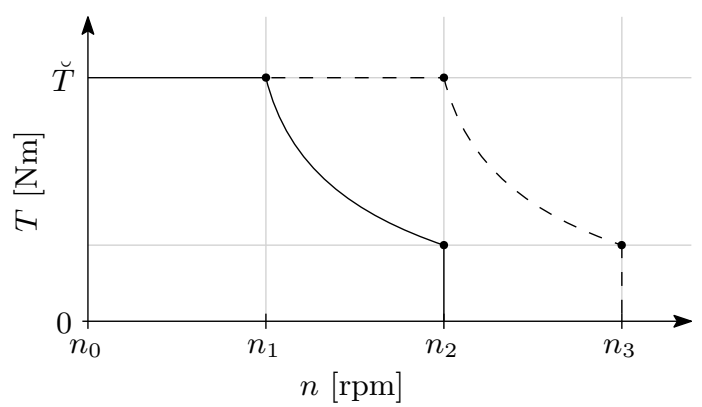

Figure 1. Idealized torque-speed characteristic obtained by application of winding reconfiguration to a multi-phase machine. The extended constanttorque range is indicated by a dashed line, and $\breve{T}$ indicates nominal torque.

range, and a fixed ratio gearbox is often sufficient. With fewer gear ratios the volume and weight of the gearbox, and torque interruptions caused by gear shifts, are minimized compared to the multi ratio gearbox approach. This contributes to the reduction of sudden, or unexpected, changes in acceleration, and limits rapid changes in jerk. The result is a smoother ride and increased passenger comfort.

This work is conducted under the European Union Modular Electric Drivetrains project, and explains an alternative to the traditional three-phase electric machine and multi ratio gearbox approach [4]. In this approach, a multi-phase electric machine is paired with a fixed ratio gearbox. The additional freedom of the multi-phase machine is used to achieve different gear ratios by intelligent commutation of the machine windings, and provide a degree of fault tolerance, for instance against short or open circuit faults, to provide limp-home functionality [5]-[7]. This principle of winding reconfiguration uses a semiconductor switch matrix to reorder the machine windings, to accommodate for the increasing EM generated voltage with higher speed. In this way a torquespeed characteristic similar to the mechanical gearbox is achieved. Winding reconfiguration allows extension of the constant-torque operating range of the electrical machine, shifting the point where field weakening is required to the higher speed region [8]. The corresponding idealized torquespeed characteristic is shown in Fig. 1. This is advantageous, as the danger of a failure while in deep field weakening, where a substantial part of the kinetic energy would be released, is 
reduced if not completely averted. As such an event leads to a high generated voltage, and resultant high winding currents, that could overload the system, or generate a sudden braking torque. Naturally, this is undesirable in an automotive setting due to the high risk of an accident.

In previous work the winding reconfiguration concept was explored to extend the operating range of a six-phase electrical machine, but kept to a bare minimum, and only applied at a fixed speed [8]. However, as winding reconfiguration is achieved purely electronically, and commutation of the semiconductor switches is virtually instantaneous, it could be applied more frequently. This work exploits this fact, by reordering the windings on the fly rather than at a fixed speed, thereby extending the operating range of the machine.

This paper has the following structure. Section II explains the principle of winding reconfiguration, introduces the switch matrix topology, and treats the modeling and simulation procedure. Section III details about the laboratory setup and the comparison with measurement results. Section IV provides the conclusions and recommendations of this work.

\section{WINDING RECONFIGURATION}

In this work a six-phase EM is used to explain the winding reconfiguration principle. Its windings are independent of each other, meaning there is no star point, which enables a free choice of the machine winding configuration, see Fig. 2a for the implementation of a single phase. It comprises two windings, that are connected through an IGBT switch matrix of two full bridges and two series switches to the supply. For simplicity the IGBTs in the switch matrix are represented by mechanical contactors, and each machine winding is represented by a single inductor. The matrix is able to connect each winding independently to the supply, as shown in Fig. 2b, and to configure the two machine windings in series, as shown in Fig. 2c and Fig. 2d. Note that each scheme of Fig. 2 contains the nodes $\mathrm{A}, \mathrm{B}, \mathrm{C}$, and $\mathrm{D}$, to clarify the connection configuration for each schematic.

Since the switch matrix provides any of the configurations of Fig. 2 as desired, it enables the possibility to alternate between the electrically equivalent series configurations of Fig. 2c and Fig. 2d. This is desirable to control the dissipation of each series switch, spread the thermal load more evenly, and extend semiconductor lifetime.

\section{A. Modeling}

Each phase is modeled as a series connection of an inductor, a resistor and a voltage source, that represent the selfinductance $L_{x}$, phase-resistance $R_{x}$, and back-EMF $e_{x}$, where $x$ represents any of the phases, see Fig. 3. The phase current is indicated by $i_{x}$, and the mutual inductance, $M_{x y}$, is indicated by double-headed arrows, where $x$ and $y$ are two separate phases. The machine windings: $a, b, \ldots, f$, are configured as two independent three-phase coil sets. Namely, the sets: $a-b-c$ and $d-e-f$. These are operated either in so-called "series" or "independent" configuration. In series configuration the windings $a-d, b-e$, and $c-f$ are interconnected, and operate

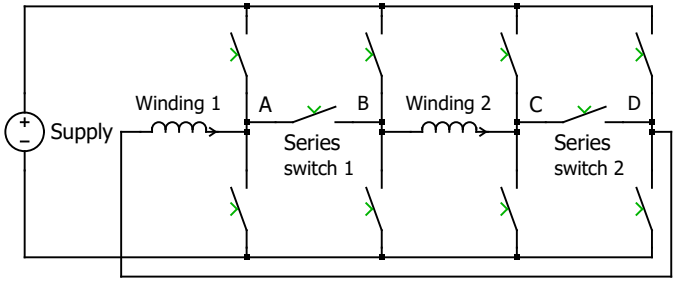

(a)

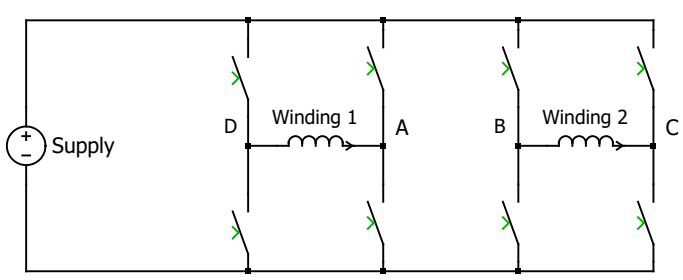

(b)

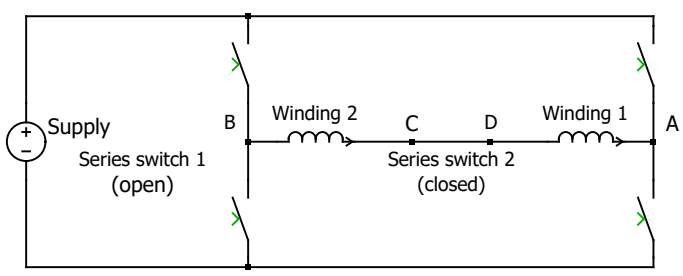

(c)

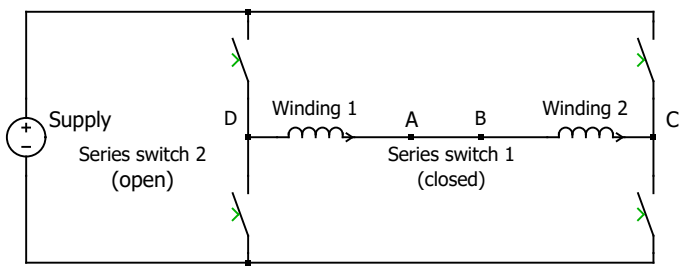

(d)

Figure 2. Schematic view of (a) the dynamic configuration for a single phase with two series switches, (b) the two phase halves in independent configuration, (c) the two phase halves in series configuration by closing series switch one, (d) the two phase halves in series configuration by closing series switch two.

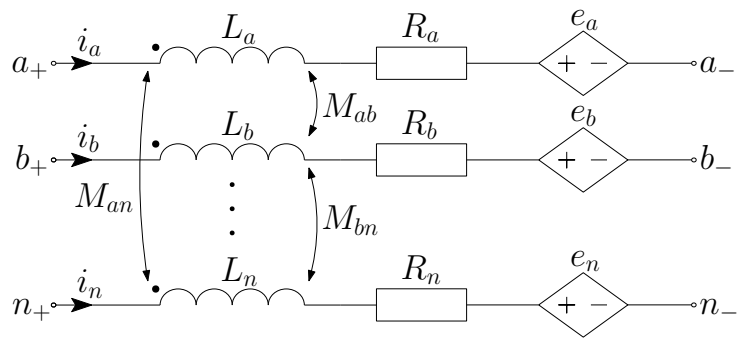

Figure 3. Schematic independent winding model for an $n$-phase machine.

as a single three-phase system. In independent configuration, both coil systems are connected separately, and operate as two individual three-phase systems. Reconfiguration from series to independent configuration takes place when the peak of the applied voltage wave, reaches the supply voltage, in this example case this occurs at approximately one-third of 


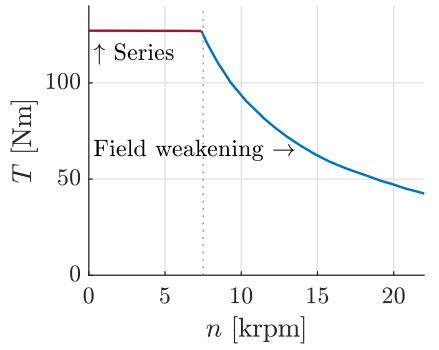

(a)

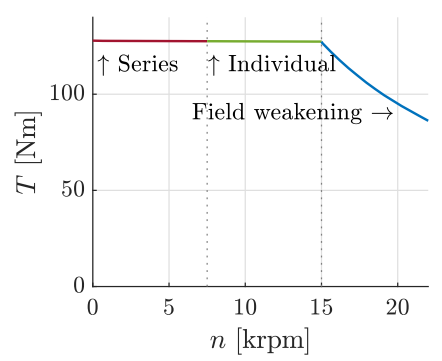

(c)

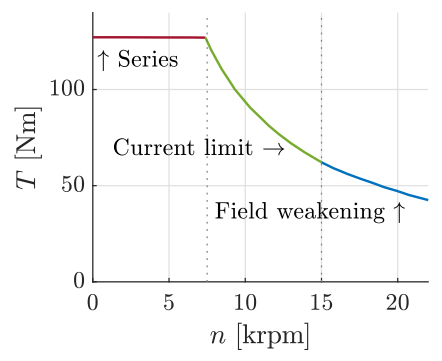

(e)

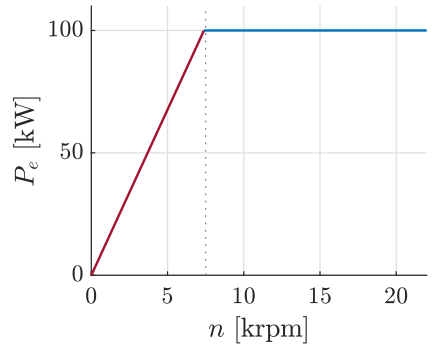

(b)

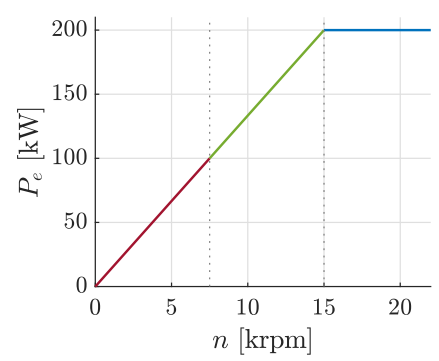

(d)

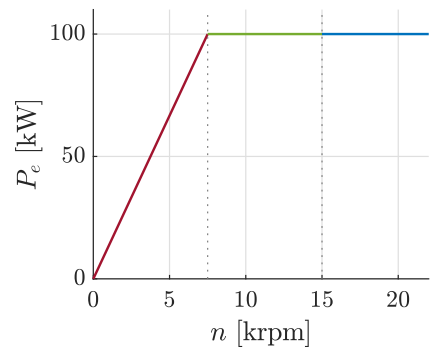

(f)
Figure 4. Torque-speed and power-speed characteristics, $(a, b)$ without winding reconfiguration, $(\mathrm{c}, \mathrm{d})$ with winding reconfiguration, $(\mathrm{e}, \mathrm{f})$ with winding reconfiguration and imposed current limit.

the maximum speed. The magnetomotive forces generated in series and independent configuration are equal. However, the amplitude of the generated voltage wave is halved in independent as opposed to the series configuration, as then only half the number of turns is present per winding. When the EM is operated in independent configuration, and rotates at twice the speed of the reconfiguration point, in this case this occurs at two-thirds of the maximum speed, the generated voltage wave again meets the supply voltage. From this point on field weakening must be used to further increase the speed.

In Fig. 4a the torque-speed characteristic for series configuration without winding reconfiguration is shown. Two distinct sections are recognizable, namely $[0 ; 7.5\rangle$ and $[7.5 ; \rightarrow\rangle$. The first section, in red, is the so-called constant-torque region, where the torque is defined by the maximum current flowing through the winding. It ends at the point where the backEMF has reached the bus voltage, beyond which field weakening is needed to further extend the speed range, the blue section. The corresponding machine electromagnetic power characteristic is shown in Fig. 4b. In Fig. 4c the torquespeed characteristic with winding reconfiguration, for two

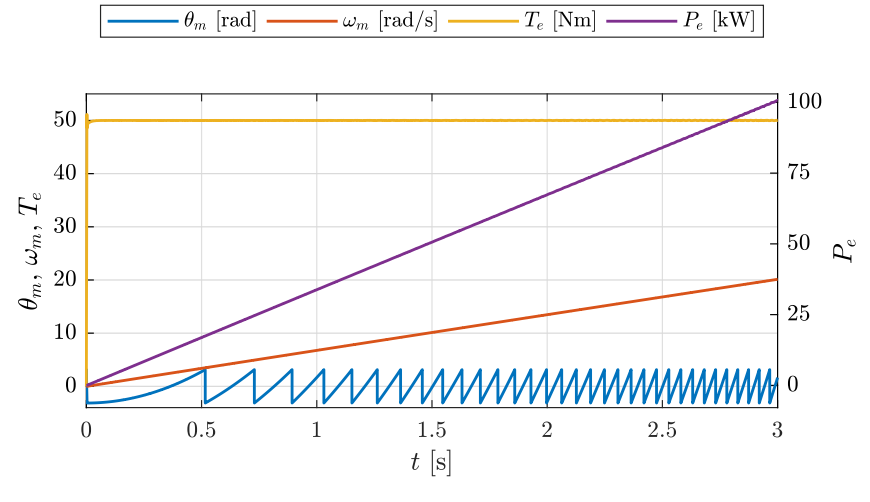

Figure 5. Simulated mechanical system response, as obtained by the torquebalance equation.

coil sets, is shown. Three distinct sections are recognizable, namely $[0 ; 7.5],[7.5 ; 15]$, and $[15 ; \rightarrow\rangle$. The first section, again in red, is identical to the previous case without winding reconfiguration. However, in this case, when the bus voltage is reached, the machine windings are reconfigured to individual configuration. This halves the back-EMF while the produced torque is retained, and doubles the effective speed range of the constant-torque region, the green section. When the back-EMF has again reached the bus voltage, field weakening remains optional to further extend the speed range, the blue section. The corresponding machine electromagnetic power characteristic is shown in Fig. 4d. Notice that the maximum power has doubled as well. In Fig. 4e the torque-speed characteristic with winding reconfiguration but without increasing the machine power is shown. This is achieved by an imposed limit on the maximum allowable current when the machine is operating in individual configuration, and a torque-speed characteristic very similar to regular field weakening is obtained while avoiding the dangers of this technique. The corresponding electromagnetic power characteristic is shown in Fig. $4 \mathrm{f}$.

\section{B. Simulation}

Winding reconfiguration for any speed is realized by reacting on the modulation index amplitude rather than on the machine speed. The modulation index is where the timings of the semiconductor switches for each converter half bridge are derived from. An amplitude of positive one results in a top switch that is always opened and a bottom switch that is always closed, and vice versa for an amplitude of negative one. A value in-between these amplitudes results in a ratio of the opened and closed state. If the machine windings are in series configuration and the absolute amplitude of the modulation index reaches one, reconfiguration to individual configuration occurs. To obtain the same magnetomotive force before and after reconfiguration, the modulation index is halved during the switchover event, such that a smooth transition is obtained.

The mechanical response, see Fig. 5, is obtained by the torque balance equation

$$
T_{e}-T_{L}=J_{m} \frac{d \omega_{m}}{d t}+B_{m} \omega_{m},
$$


Table I

MeAsured PARAMETERS OF THE SIX-PHASE EM.

\begin{tabular}{|c|c|c|c|c|c|c|c|c|}
\hline Parameter & \multicolumn{6}{|c|}{ Value } & Unit & Description \\
\hline$R$ & \multicolumn{6}{|c|}{2.60} & $\Omega$ & Phase resistance \\
\hline \multirow{6}{*}{$L$} & {$[33.0$} & -1.25 & 0 & 0 & 0 & $-1.25]$ & \multirow{6}{*}{$\mathrm{mH}$} & \multirow{6}{*}{ Inductance matrix } \\
\hline & -1.25 & 33.0 & -1.25 & 0 & 0 & 0 & & \\
\hline & 0 & -1.25 & 33.0 & -1.25 & 0 & 0 & & \\
\hline & 0 & 0 & -1.25 & 33.0 & -1.25 & 0 & & \\
\hline & 0 & 0 & 0 & -1.25 & 33.0 & -1.25 & & \\
\hline & -1.25 & 0 & 0 & 0 & -1.25 & 33.0 & & \\
\hline$K_{e 1}$ & \multicolumn{6}{|c|}{1.91} & Vs/rad & $1^{s t}$ harmonic EMF constant \\
\hline$K_{e 3}$ & \multicolumn{6}{|c|}{0.20} & Vs/rad & $3^{r d}$ harmonic EMF constant \\
\hline$J_{m}$ & \multicolumn{6}{|c|}{0.17} & $\mathrm{kgm}^{2}$ & Powertrain inertia \\
\hline$B_{m}$ & \multicolumn{6}{|c|}{$50 \cdot 10^{-3}$} & $\mathrm{Nms} / \mathrm{rad}$ & Mechanical friction \\
\hline
\end{tabular}

where $T_{e}$ is the EM produced electromagnetic torque, $T_{L}$ the load torque, $J_{m}$ the total inertia of the rotating powertrain, $B_{m}$ the combined mechanical friction or damping coefficient, $\omega_{m}$ the mechanical speed, and $t$ time. Simple PI-controllers together with the Park and Clarke transforms are used to regulate the machine to a desired torque or speed under various loads, and during reconfiguration events [9]. Measured parameters of the powertrain are given in Table I, note that the inductance is given as a band matrix that combines both the self and mutual inductance for all six machine windings.

In Fig. 6a the simulated modulation index of the accelerating six-phase EM, with a single reconfiguration event at a fixed speed, the same approach as used in previous work, is shown over normalized time. Reconfiguration in this case is governed by the mechanical machine speed. At first, the machine windings are configured in series, as indicated by the blue section, and the machine is operating at low speed. When the machine has accelerated sufficiently such that the absolute modulation index amplitude has reached one, reconfiguration to individual configuration occurs, as indicated by the orange section. This approach is very easily implemented from a control point of view, but results in uneven thermal loading of the semiconductor switches. As the series switch remains closed for a long period of time, during which it continuously carries the total phase current, a low on resistance is desirable.

The approach of this work is shown in Fig. 6b, where the simulated modulation index of the accelerating six-phase EM with multiple reconfiguration events is shown. In this case, reconfiguration is governed by the amplitude of the modulation index. At first, the machine windings are configured in series, as indicated by the blue section, and the simulation result is identical to Fig. 6a. Reconfiguration occurs when the machine has accelerated sufficiently, this time up to two times per cycle, as indicated by the orange sections. This approach is more complex to implement from a control point of view, but results in better thermal loading of the switches as the series switch is only engaged when required. Additionally, the thermal load is spread when the two series switches are used alternately.

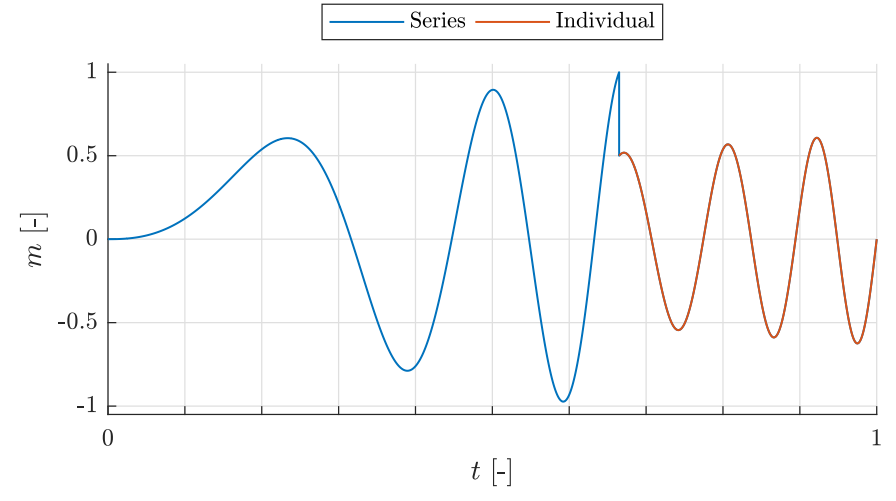

(a)

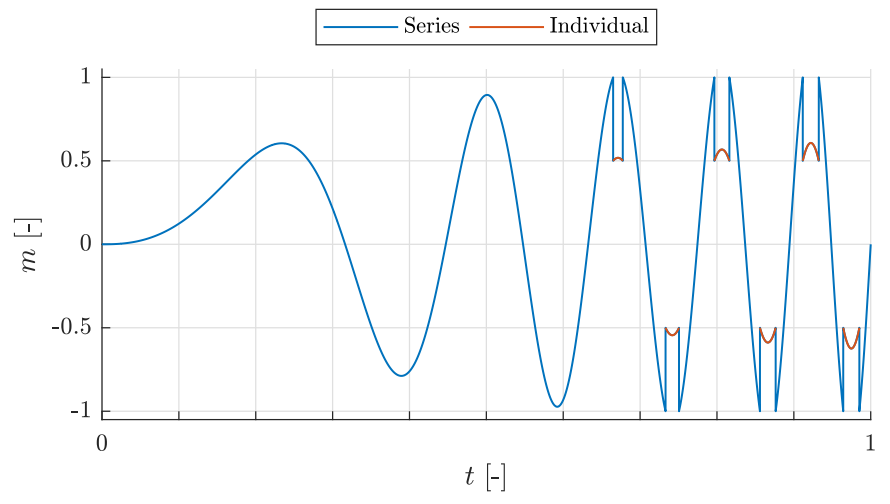

(b)

Figure 6. Simulated modulation index of a single phase over a normalized time cycle with reconfiguration, (a) at a fixed speed, (b) on the fly whenever the back-EMF exceeds the bus voltage.

\section{LABORATORY TEST SETUP AND COMPARISON}

To validate the winding reconfiguration method a test setup has been built. It consists of four major parts: the six-phase EM, the power stage, the DC load machine, and the control hardware. In Fig. 7a the six-phase EM is shown in back-toback configuration with the DC load machine, the machines are coupled by a shaft which includes a torque sensor and 


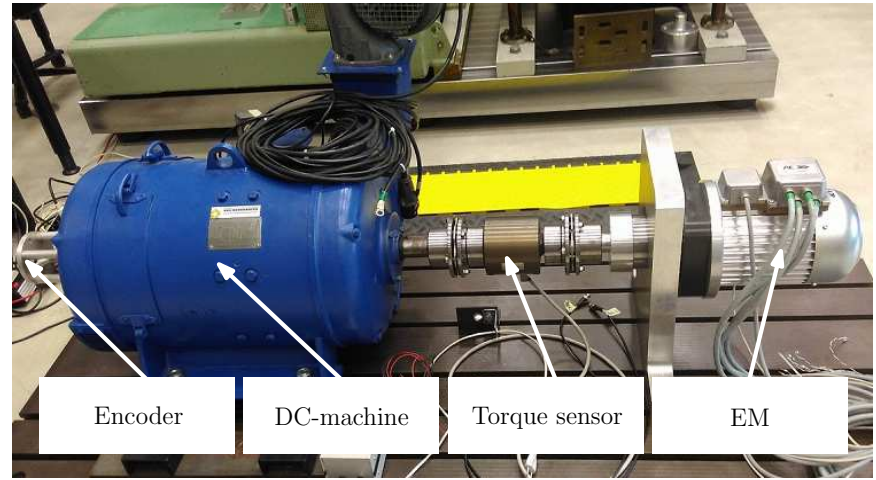

(a)

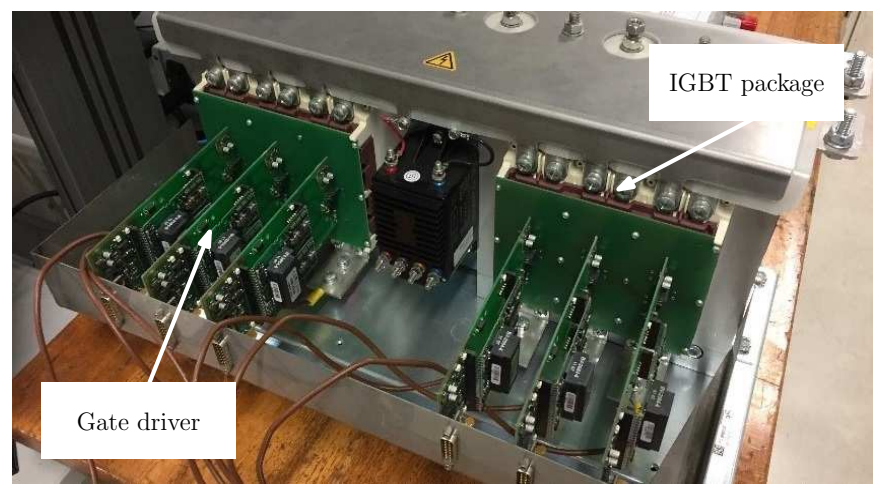

(b)

Figure 7. (a) Laboratory setup with six-phase EM and DC load machine, shaft encoder, and torque sensor, (b) power stage for two windings, with six half-bridges in two IGBT packages, and their six gate driver cards.

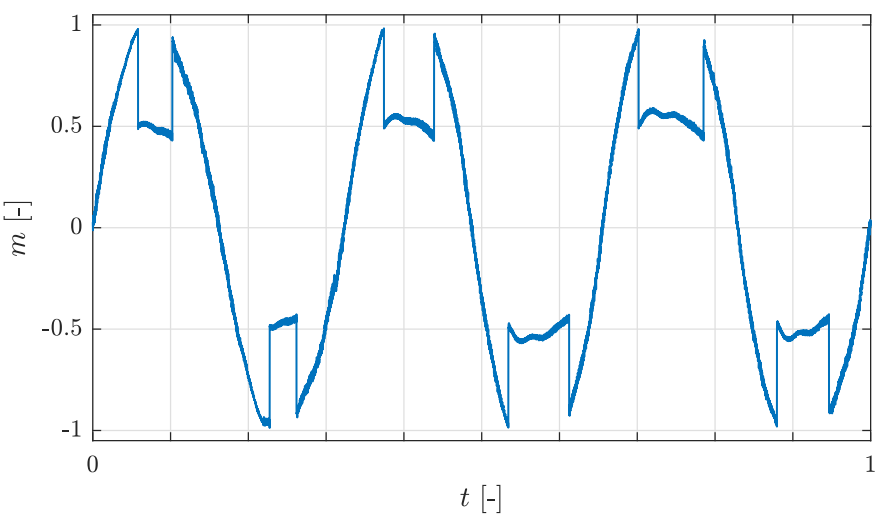

Figure 8. Measured modulation index for a single phase with multiple reconfiguration events over normalized time.

position encoder. The power stage comprises twelve IGBTs that make up the full-bridges and series switches for a single phase of the six-phase machine. In Fig. $7 \mathrm{~b}$ the power stage is shown for two phases. In total three of these stages are applied to supply all windings of the six-phase machine. The control hardware is developed in Simulink and deployed on a dSPACE MicroLabBox. The measured modulation index for a single phase of the test setup is shown in Fig. 8.

\section{CONCLUSIONS AND RECOMMENDATIONS}

The winding reconfiguration control technique for a multiphase machine has been described in this work, its modeling procedure and simulation results have been discussed, and the technique was verified by measurement data obtained from a test setup which featured a six-phase EM. It is clear that a multi-phase machine provides more flexibility and opens new possibilities compared to a regular three-phase machine, such as extension of the constant-torque or speed range, and increased reliability by allowing for a degree of fault tolerance. However, this comes at the cost of more complicated control algorithms, and an increased amount of semiconductor switches. Moreover, due to the lack of a star point it is not inherently guaranteed that the voltage between phases is balanced, and this might require active control to enforce. Extension of the speed range by reconfiguration of the EM windings on the fly has been achieved in this work. By application in an electric vehicle, this could result in a reduction of the required amount of gear ratios, as the mechanical action of changing gears is replaced by an electronic one, such that the volume and weight of the gearbox is reduced. Moreover, winding reconfiguration has been shown to be virtually instantaneous, which avoids torque pulsations as switching between series and individual configuration is smooth, which in turn results in a smooth ride. Additionally, the switching regime could be enhanced to further increase the efficiency, and the control algorithm improved to provide fault tolerant behavior e.g. limp-home functionality.

\section{ACKNOWLEDGMENT}

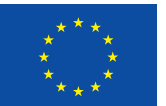

This paper is part of a project that has received funding from the European Union's Horizon 2020 research and innovation programme under grant agreement No 769953.

\section{REFERENCES}

[1] ICCT (International Council on Clean Transportation), Electric vehicle capitals: Accelerating the global transition to electric drive, Briefing, Oct. 2018.

[2] J. R. Hendershot and T. J. E. Miller, Design of Brushless PermanentMagnet Machines. Acco C.V., 2010, ISBN: 978-9033456862.

[3] T. Gerrits, C. G. E. Wijnands, J. J. H. Paulides, and J. L. Duarte, "Electrical gearbox equivalent by means of dynamic machine operation", Proceedings of the 2011 14th European Conference on Power Electronics and Applications, 2011.

[4] ModulED. (2017). Modular electric drivetrains: Next generation electric drivetrains for fully electric vehicles, focusing on high efficiency and low cost, [Online]. Available: http://moduled-project.eu/. [Accessed: 29 March 2019].

[5] L. Parsa, "On advantages of multi-phase machines", in 31st Annual Conference of IEEE Industrial Electronics Society, 2005. IECON 2005., IEEE, 2005.

[6] T. Gerrits, C. G. E. Wijnands, J. J. H. Paulides, and J. L. Duarte, "Fault-tolerant operation of a fully electric gearbox equivalent", IEEE Transactions on Industry Applications, vol. 48, no. 6, pp. 1855-1865, Nov. 2012.

[7] B. Mecrow, A. Jack, J. Haylock, and J. Coles, "Fault tolerant permanent magnet machine drives", in Seventh International Conference on Electrical Machines and Drives, IEE, 1995.

[8] T. Gerrits, C. G. E. Wijnands, J. J. H. Paulides, and J. L. Duarte, "Dynamic machine operation transitions", in 2013 IEEE Vehicle Power and Propulsion Conference (VPPC), IEEE, Oct. 2013.

[9] G. Terörde, Electrical Drives and Control Techniques. Motor Design Books LLC, 2004, ISBN: 978-0984068708. 